\title{
Cancer mortality in a northern Italian cohort of rubber workers
}

\author{
EVA NEGRI, ${ }^{1}$ G PIOLATTO, ${ }^{2}$ E PIRA, ${ }^{2}$ A DECARLI, ${ }^{3}$ J KALDOR, ${ }^{4}$ C LA VECCHIA ${ }^{15}$
}

From the "Mario Negri" Institute for Pharmacological Research,' 20157 Milan, Institute of Occupational Health, ${ }^{2}$ University of Turin, 10126 Turin, Institute of Medical Statistics, ${ }^{3}$ University of Milan, 20133 Milan, Italy, International Agency for Research on Cancer, ${ }^{4} 69372$ Lyon, France, and Institute of Social and Preventive Medicine, ${ }^{5}$ University of Lausanne, 1005 Lausanne, Switzerland

ABSTRACT An analysis of the mortality of a cohort of 6629 workers employed from 1906 to 1981 in a $\frac{\mathbb{\infty}}{3}$ rubber tyre factory in northern Italy (978 deaths and over 133000 man-years at risk) showed that the all cause mortality ratio was slightly lower than expected $(0.91)$. Overall cancer mortality was close to. expected $(275 v 259 \cdot 4)$ but there were significant excess rates for two cancer sites: pleura (9 observed $v_{\perp}^{N}$ 0.8 expected, which may be due to the use of fibre containing talc) and bladder (16 observed $v 8.80$ expected). Death rates were not raised for other sites previously associated with employment in the ${ }_{-}$ rubber industry, such as cancers of the lung and brain, leukaemias, or lymphomas. The substantiallyes reduced relative risk of pleural cancer among workers first employed after $1940(R R=0.05 \stackrel{\mathbb{O}}{\mathbb{T}}$ compared with before 1940) probably reflected improvements in working conditions over more $\frac{\mathbb{\Phi}}{3}$ recent periods. For cancer of the bladder, the relative risk was also lower for workers first engaged $\bar{\Phi}_{-}$ after 1940. Thus no appreciable risk for any disease was apparent for workers employed over the past ${ }_{\vec{B}}^{-}$ four decades. Analysis for each of the 27 job categories showed a substantial excess for cancer of theo pleura in the mechanical maintenance workers ( 4 observed $v 0.17$ expected); an excess of cancer of the lung $(21 v 13.48)$ was also present in this job category.

Several epidemiological studies have indicated that workers in the rubber industry experience a raised risk of cancer at several sites including the bladder and other genitorurinary organs, stomach, lung, brain, lymphoreticular system, and skin..$^{1-7}$ The considerable variation among studies can only partly be attributed to differences in type or level of exposure or both. Other possible explanations are confounding factors and chance due to small numbers of cases.

For example, the association between working in the rubber tyre manufacturing industry and the risk of bladder cancer may be plausibly explained in terms of exposure to naphthylamine, benzidine, and other aromatic amines, ${ }^{36}$ whereas that with stomach cancer finds no obvious explanation and may perhaps be accounted for by differences in the social class distribution of rubber workers. For other tumours, such as brain ${ }^{1}$ or lymphoreticular neoplasms, ${ }^{7}$ little is known in aetiological terms, but a possible association with some (as yet unidentified) chemical(s) in the

Accepted 7 November 1988 rubber industry has been suggested by epidemiologicalo observations.

Given this still unsettled state of knowledge, we decided to analyse data from a cohort of 6629 workers employed in a rubber tyre factory in the district of Turin, northern Italy, between 1906 and 1981. Besides:standard descriptive analyses based on the computa- $-\Phi$ tion of observed and expected numbers of deaths from 3 selected causes, we applied log linear models to obtain estimates of the effect of calendar period and age at first exposure, duration of exposure, and period sinceo last exposure. Furthermore, analyses were performed 2 to identify job categories particularly at risk.

\section{Subjects and methods}

\section{CHARACTERISTICS OF THE STUDY COHORT}

The cohort comprised all men who had worked for at 0 least one year in the factory between 1946 and 1981. Of $\mathrm{CW}_{\mathrm{W}}$ these, $9 \%$ who could not be traced were excluded,0 leaving 6629 subjects under study.

Dates of birth, employment(s), and termination of employment(s), the last known address, and detailed@्? 
job history were obtained from personnel records at the factory. Death certificates were obtained from registration offices in the municipality of death. Further verification of vital status was obtained from registries of current residence.

For the present analysis, follow up began at 1 January 1946 and ended at 31 December 1981. A total of 978 deaths was registered in this period from 133678 man-years of observation.

\section{DATA ANALYSIS AND MODELS OF RISK}

The expected numbers of deaths from selected cancer sites and all causes were computed using national death rates for each five year calendar period and age group. All cause national death rates for each quinquennium of age are published by the Central Institute of Statistics (ISTAT) from 1955 onwards. ${ }^{89}$ Rates for the late 1950s were applied to the period 1946-54. Observed and expected numbers were tabulated by year of first employment, duration of employment, and period since employment ended.

As retirement or change of job may in some cases have been due to the disease itself, one year was subtracted from the date of death. Changing this interval to two or three years did not materially modify any of the results.

For each of 27 job categories the cohort was then subdivided into two strata: (1) workers who spent at least one year in that job category and (2) workers who did not. Observed and expected numbers of deaths were computed separately for the two strata.

To examine the effect of several temporal variables simultaneously, the multiplicative model ${ }^{10}$ was fitted ${ }^{\prime \prime}$ to the death rates which were significantly raised. Under this model, each temporal variable related to exposure (period of first employment, age at first exposure, duration of exposure, and period since last employment) is assumed to act multiplicatively with each other and on the man-years at risk.

\section{Results}

The total number of deaths observed was close to expected $(978 v 1033)$. Table I gives observed and expected numbers for selected cancer sites previously associated with the rubber industry. There was no excess mortality for cancers of the lung, stomach, brain, lymphoreticular neoplasms, leukaemias, or several sites previously reported to be related to rubber manufacture. There was, however, considerably increased mortality for cancer of the pleura ( 9 observed $v 0.8$ expected) and a significant excess for cancer of the bladder ( 16 observed $v 8.8$ expected).

Table 2 gives observed and expected numbers of deaths for lung cancer, the two sites showing raised
Table 1 Mortality experience from selected cancer sites $*$ in a cohort of workers in a rubber tyre factory in northern Italy. Expected numbers are based on national death rates in each five year calendar period and age group. Deaths and manyears beyond age 80 are excluded

\begin{tabular}{|c|c|c|c|}
\hline & $\begin{array}{l}\text { No of deaths } \\
\text { Obs: Exp }\end{array}$ & $O / E$ & $(95 \% C I)$ \\
\hline $\begin{array}{l}\text { Oesophagus } \\
\text { Stomach } \\
\text { Liver } \\
\text { Pancreas } \\
\text { Larynx } \\
\text { Lung } \\
\text { Pleura } \\
\text { Skin } \\
\text { Bladder } \\
\text { Kidney and other } \\
\text { urinary sites }\end{array}$ & $\begin{array}{c}7: 6 \cdot 87 \\
35: 45 \cdot 08 \\
3: 5 \cdot 60 \\
2: 7 \cdot 56 \\
13: 10 \cdot 31 \\
64: 63 \cdot 16 \\
9: 0 \cdot 82 \\
3: 2 \cdot 36 \\
16: 8 \cdot 75 \\
5: 3 \cdot 77\end{array}$ & $\begin{array}{r}1.02 \\
0 \cdot 78 \\
0 \cdot 54 \\
0 \cdot 26 \\
1.26 \\
1.01 \\
10.98 \\
1.27 \\
1.83 \\
1.33\end{array}$ & $\begin{array}{l}(0.42-2 \cdot 10) \\
(0.54-1.08) \\
(0 \cdot 11-1 \cdot 56) \\
(0.03-0.96) \\
(0.67-2 \cdot 16) \\
(0.79-1.29) \\
(5.23-20.86) \\
(0.26-3 \cdot 71) \\
(1.05-2.96) \\
(0.43-3.09)\end{array}$ \\
\hline $\begin{array}{l}\text { Brain } \\
\text { Leukaemias } \\
\text { Lymphomas } \\
\text { All other cancers } \\
\text { All other causes }\end{array}$ & $\begin{array}{c}9: 10 \cdot 19 \\
8: 8 \cdot 83 \\
7: 9 \cdot 43 \\
94: 76 \cdot 62 \\
703: 773 \cdot 64\end{array}$ & $\begin{array}{l}0.88 \\
0.91 \\
0.74 \\
1.23 \\
0.91\end{array}$ & $\begin{array}{l}(0.40-1.67) \\
(0.39-1.79) \\
(0.30-1.53) \\
(1.00-1.51) \\
(0.84-0.94)\end{array}$ \\
\hline
\end{tabular}

*On the basis of the International Agency for Research on Cancer monograph on the rubber industry. ${ }^{3}$

standardised mortality ratios (SMRs) in this study (pleura and bladder), all other cancers, and all other causes of death categorised separately by period of first employment, age at first exposure, duration of employment, and period since last employment.

In relation to period of first employment, the SMRs were generally higher for subjects first employed before 1940 and tended to decrease for workers engaged in more recent calendar periods. Although the SMR ratio for total mortality in workers employed from 1940 onwards was $0 \cdot 84$, the ratios for cancer of the pleura and bladder remained above unity, in the former case substantially so.

No clear pattern was observed in relation to age at first exposure (although SMRs for total mortality and bladder cancer were somewhat higher for subjects exposed at earlier ages) or duration of employment, and the pleura and bladder mortality both decreased considerably after the end of employment. No consistent pattern of risk after employment emerged for the other cancer sites or non-cancer mortality.

Table 3 gives the parameter estimates from the multiplicative model under which the effect of the four variables considered (period of first employment, age at first exposure, duration of exposure, and period since last exposure) was estimated simultaneously for pleura and bladder cancer. These estimates, together with the corresponding standard errors, are expressed in relation to one of the categories of the variable, arbitrarily chosen as referent. The exponential of each estimate gives the risk for the corresponding category, relative to the referent one. Tests of statistical significance may be obtained by comparing the ratio of 


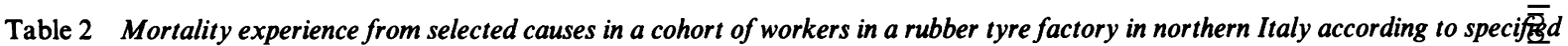
variables. Expected (Exp) numbers are based on national death rates in each five year calendar period and age group. Deaths and man-ea beyond age 80 are excluded

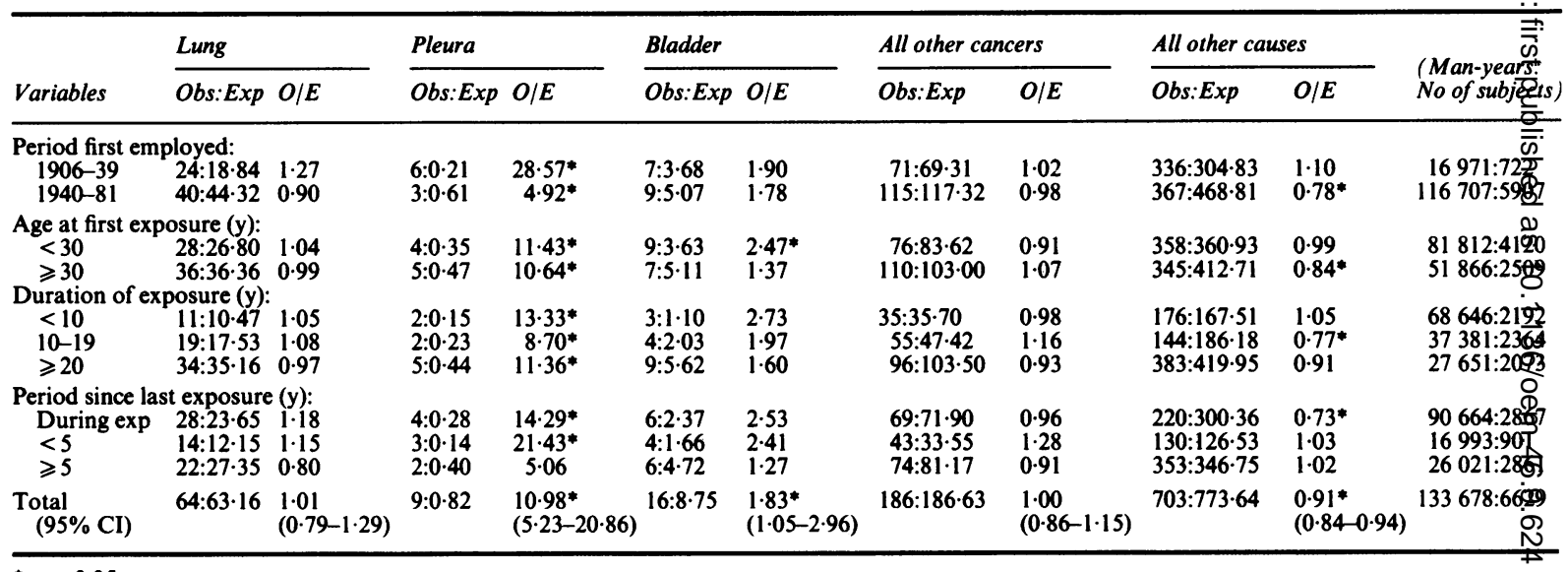

$* \mathrm{p}<0.05$.

each parameter estimate to its standard error with a standardised normal deviate.

In the context of hypothesis testing against the full models, for pleural cancer three of the four models with one factor only-that is, those analysing age at first employment and duration or period since last employment-gave significant deviance differences, whereas that with period gave a non-significant difference of 3.8 with four degrees of freedom. For bladder cancer significant differences were observed against the models including only age at first exposure or period since last exposure but not period of first employment or duration. A significant reduction in deviances between the four three-factor models and the full one was given by inclusion of period for pleural $(\mathrm{p}<0.001)$.

Under the full model the relative risk of pleural cancer was significantly lower in workers first employed after 1940. The risk tended to increase with older age at first exposure, though differences were not significant, but no consistent pattern was evident with duration. Likewise, no clear pattern was evident in relation to period since last exposure. Compared with workers who had died during employment in the rubber plant, the relative risk was above unity for theperiod one to four years after exposure but fell towardse unity for longer periods.

For bladder cancer mortality, the relative risk was $\stackrel{\overrightarrow{\mathbb{D}}}{3}$ lower for workers first employed after 1939, ando increased with increasing duration of exposure and period since last exposure. None of these estimates $\overrightarrow{0}$ was, however, statistically significant.

The analysis of observed and expected number deaths for each of the 27 job categories showed systematic excess except that for workers who spent at least one year in the mechanical maintenance job? category. Table 4 gives the results for this and othero major selected job categories. The SMR of pleura cancer for workers ever been in the mechanicalo maintenance job category rose to 23.53 (4 observed $v^{3}$ 0.17 expected). The same workers showed an increased, though not significantly, lung cancer mortality ( 21 observed $v 13.48$ expected, SMR $=1.58)$.

No other pronounced increase of risk was evident 3 for any other job category, apart from the "variouso services" in which mortality was raised for almost any. cause, probably on account of selective inclusion in this category of subjects who were ill.

Table 3 Parameter estimates by fitting period of first employment, age at first exposure, duration of exposure, and period since last exposure to risk of pleural and bladder cancer in a rubber tyre factory in northern Italy

\begin{tabular}{|c|c|c|c|c|c|c|c|}
\hline \multirow[b]{2}{*}{ Variables } & \multirow[b]{2}{*}{ Level } & \multicolumn{3}{|c|}{ Pleural cancer } & \multicolumn{3}{|c|}{ Bladder cancer } \\
\hline & & Parameter & $(S E)$ & Relative risk & Parameter & $(S E)$ & Relative risk \\
\hline $\begin{array}{l}\text { Period of first employment } \\
\text { Age at first exposure (y) } \\
\text { Duration of exposure (y) } \\
\text { Period since last exposure (y) }\end{array}$ & $\begin{array}{l}1906-39^{*} \\
1940-79 \\
<30^{*} \\
\geqslant 30 \\
<20^{*} \\
\geqslant 20 \\
\text { During exp* } \\
1-4 \\
\geqslant 5\end{array}$ & $\begin{array}{r}0.00 \\
-3.10 \\
0.00 \\
1.10 \\
0.00 \\
-0.54 \\
0.00 \\
1.14 \\
0.19\end{array}$ & $\begin{array}{l}\overline{0.94} \\
\overline{0.68} \\
\overline{0.93} \\
\overline{0.81} \\
0.89\end{array}$ & $\begin{array}{l}1 \\
0.05 \\
1 \\
3.01 \\
1 \\
0.58 \\
1 \\
3 \cdot 12 \\
1.21\end{array}$ & $\begin{array}{r}0.00 \\
-0.93 \\
0.00 \\
0.39 \\
0.00 \\
0.89 \\
0.00 \\
0.95 \\
1.00\end{array}$ & $\begin{array}{l}\overline{0.71} \\
\overline{0.52} \\
\frac{-}{0.70} \\
\overline{0.66} \\
0.59\end{array}$ & $\begin{array}{l}1 \\
0.39 \\
1 \\
1 \cdot 48 \\
1 \\
2 \cdot 43 \\
1 \\
2 \cdot 59 \\
2 \cdot 72\end{array}$ \\
\hline
\end{tabular}




\section{Discussion}

The observation of this cohort of workers in a rubber factory in northern Italy, based on a total of 978 deaths and over 133000 man-years at risk, showed a mortality ratio for all causes slightly lower than expected $(0.91)$, probably explainable in terms of a "healthy worker" effect. Overall cancer mortality was close to expected but there were significant excess rates for two sites, pleura ( 9 observed $v 0.8$ expected) and bladder ( 16 observed $v 8.8$ expected). Death rates were not raised for other cancer sites associated with employment in the rubber industry in previous studies, such as stomach, lung, brain, leukaemias, or lymphomas. ${ }^{3}$ With the sample size of this study, it was possible to exclude at the conventional $95 \%$ probability, relative risks above 1.3 for lung cancer, 1.1 for stomach, 1.7 for brain, 1.8 for leukaemias, and 1.5 for other lymphoreticular neoplasms.

Both the positive findings, and the absence of confirmation of some previously observed excess risks of cancer in rubber workers, are of some interest, chiefly in consideration of the relatively large size of this cohort. ${ }^{3}$ This study, however, has some obvious limitations, too. Firstly, all the diagnoses were based on death certification only. Secondly, the follow up process, although satisfactory, still left $9 \%$ untraced, with obviously larger rates of loss in men who left the factory at younger ages in earlier calendar periods. Thirdly, the use of national rates for the computation of expected numbers should be discussed. In the mid1970s, however, the province where the factory was located (Turin) had death rates not appreciably different from the national ones: SMRs were 113 for all causes, 109 for all neoplasms, 97 for cancers of the respiratory organs, and 115 for cancers of the urinary organs. ${ }^{12}$

Since death rates by province are available in Italy only from 1968 onwards, we considered that the errors caused by using the national mortality data for the earlier periods were smaller than those which would result from the use of rates from the 1970s in the computation of expected numbers for deaths observed in the 1940-60s.

The application of multiplicative models of risk to the death rates from cancers of the pleura and bladder indicated that, after allowance for other temporal factors considered, the relative risks were appreciably reduced among workers first employed after 1940, probably reflecting improvements in working conditions over more recent decades; the latest engagement date for a worker dead from pleural cancer was 1954 . The cut off point of 1940 , nevertheless, was chosen mainly on statistical grounds, since no explicit information was available on changes in exposure patterns which may have occurred in the follow up period. Furthermore, the risk of bladder cancer appeared to increase with duration of employment.

The raised risk of bladder cancer in several cohorts of rubber workers has been related to the use of $\beta$ naphthylamine and other aromatic amines, ${ }^{1314}$ but no information is available in terms of levels of exposure in this rubber tyre plant. Furthermore, it is still uncertain whether phenyl- $\beta$-napthlylamine (the only one aromatic amine used in this factory) is carcinogenic in man. ${ }^{15}$

The excess risk of pleural cancer observed in this cohort might possibly be related to the use in earlier periods of fibre containing talc as antitackling agent in tyre manufacturing and storage. ${ }^{16}$ This excess should be considered with due caution, however, since the diagnoses were based on death certificates only. Hence, there are serious difficulties in terms of diagnostic reliability for observed and expected numbers, mostly for earlier calendar periods. ${ }^{17}$

Analyses of a large American cohort of insulation workers indicated that the effect of exposure to asbestos on the risk of mesothelioma is independent from age at first exposure ${ }^{18}$ suggesting an early stage effect in the carcinogenic process. ${ }^{192}$ The data of that study were analysed in terms of death rates in separate strata of time since first exposure. A similar analysis based on this dataset (table 5) is in broad agreement with that study, since there was a substantial increase in absolute risk with period since first exposure. The observation that the absolute risk increased (though not significantly) with age at first exposure and the fall of the relative risk after five years since last exposure do not agree with an early stage effect; it is none the less likely that the present data are too scanty to provide reliable information on these factors or that heterogeneity in job classifications may produce spurious trends.

Other explanations may be that the possible

Table 4 Observed and expected numbers for selected causes of death among workers who had spent at least one year in selected job categories of a rubber tyre factory in northern Italy. Deaths and man-years beyond age 80 are excluded

\begin{tabular}{|c|c|c|c|c|c|c|c|c|c|}
\hline & \multicolumn{2}{|l|}{ Lung } & \multicolumn{2}{|l|}{ Pleura } & \multicolumn{2}{|l|}{ Bladder } & \multicolumn{2}{|c|}{ All other causes } & \multirow[b]{2}{*}{ Man-years } \\
\hline & Obs:Exp & $O / E$ & Obs:Exp & $O / E$ & Obs:Exp & $O / E$ & Obs:Exp & $O / E$ & \\
\hline $\begin{array}{l}\text { Mechanical maintenance } \\
\text { Milling } \\
\text { Extruding and calendering } \\
\text { Tyre building } \\
\text { Various services }\end{array}$ & $\begin{array}{c}21: 13 \cdot 48 \\
6: 10 \cdot 48 \\
11: 9 \cdot 98 \\
13: 12 \cdot 16 \\
25: 11 \cdot 12\end{array}$ & $\begin{array}{l}1 \cdot 56 \\
0 \cdot 57 \\
1 \cdot 10 \\
1 \cdot 07 \\
2 \cdot 25 *\end{array}$ & $\begin{array}{l}4: 0 \cdot 17 \\
1: 0 \cdot 14 \\
2: 0 \cdot 13 \\
0: 0 \cdot 16 \\
3: 0 \cdot 18\end{array}$ & $\begin{array}{c}23 \cdot 53^{*} \\
7 \cdot 49^{*} \\
15 \cdot 38^{*} \\
16 \cdot 66^{*}\end{array}$ & $\begin{array}{l}1: 2 \cdot 10 \\
4: 1 \cdot 43 \\
2: 1 \cdot 76 \\
3: 1 \cdot 54 \\
7: 2 \cdot 00\end{array}$ & $\begin{array}{l}0 \cdot 48 \\
2 \cdot 80 \\
1 \cdot 14 \\
1.95 \\
3 \cdot 50^{*}\end{array}$ & $\begin{array}{l}212: 221 \cdot 29 \\
166: 159 \cdot 12 \\
122: 143 \cdot 34 \\
154: 188 \cdot 22 \\
236: 205 \cdot 00\end{array}$ & $\begin{array}{l}0.96 \\
1.04 \\
0.85 \\
0.82 \\
1 \cdot 15^{*}\end{array}$ & $\begin{array}{ll}24 & 667 \\
21 & 631 \\
23 & 598 \\
32 & 419 \\
23 & 631\end{array}$ \\
\hline
\end{tabular}

$* p<0.05$ 
Table 5 Distribution of deaths from pleural cancer in a rubber tyre factory in northern Italy by period since first exposure and $\overline{\bar{z}}$ age at first exposure

\begin{tabular}{|c|c|c|c|c|c|c|}
\hline & \multicolumn{4}{|c|}{ Years since first exposure } & \multirow{2}{*}{\multicolumn{2}{|c|}{ Total }} \\
\hline & \multicolumn{2}{|l|}{$\leqslant 25$} & \multicolumn{2}{|l|}{$>25$} & & \\
\hline & Obs/Man-years & Death rate/100 000 & Obs/Man-years & Death rate $/ 100000$ & Obs/Man-years & Death rate/100000 \\
\hline $\begin{array}{l}\text { Age at first exp } \\
\quad<30 \\
\geqslant 30 \\
\text { Total }\end{array}$ & $\begin{array}{l}\text { osure (y): } \\
1 / 65911 \\
2 / 44536 \\
3 / 110447\end{array}$ & $\begin{array}{l}1 \cdot 5 \\
4 \cdot 5 \\
2.7\end{array}$ & $\begin{array}{l}3 / 15901 \\
3 / 7330 \\
6 / 23231\end{array}$ & $\begin{array}{l}18.9 \\
40.9 \\
25.8\end{array}$ & $\begin{array}{l}4 / 81812 \\
5 / 51866 \\
9 / 133678\end{array}$ & $\begin{array}{l}4.9 \\
9 \cdot 6 \\
6.7\end{array}$ \\
\hline
\end{tabular}

exposure to asbestos occurred before employment in the rubber factory or that some other pleural carcinogen with different characteristics of risk was present in this working environment.

The excess of pleural cancer seemed higher in the mechanical maintenance job category where an excess of lung cancer was also evident. Possibly workers in that category were heavily exposed to asbestos or other fibres while cleaning and repairing machines.

In conclusion, this study confirmed an excess of cancers of the bladder in a large cohort of rubber workers which, however, was reduced in workers employed after 1940 . Furthermore, there was a striking excess of pleural cancer, especially in workers engaged before 1940, but not of cancer of the brain, lymphomas, or leukaemias. No substantial excess risk for any disease was apparent for workers engaged over the past four decades.

This work was conducted within the framework of the CNR (Italian National Research Council) applied project "Oncology" (contract No 87.01544.44). The contributions of the Italian League Against Tumours and the Italian Association for Cancer Research, Milan, Italy, are gratefully acknowledged. We thank Professor Julian Peto, Professor Benedetto Terracini, and Dr Lorenzo Simonato for helpful comments, and Ms Judy Baggott, Flavia Boniardi, and the GA Pfeiffer Memorial Library Staff for editorial help.

\section{References}

1 Burch JD, Craib KJP, Choi BCK, Miller AB, Risch HA, Howe GR. An exploratory case-control study of brain tumors in adults. JNCI 1987;78:601-9.

2 Case RAM, Hosker ME. Tumour of the urinary bladder as an occupational disease in the rubber industry in England and Wales. British Journal of Preventive and Social Medicine 1954;8:39-50.
3 International Agency for Research on Cancer. Monographs on the evaluation of the carcinogenic risk of chemicals to humans. Vol 28. The rubber industry. Lyon: IARC, 1982.

4 Parkes HG. Epidemiology and etiology of human bladder cancer. Occupational bladder cancer in the British rubber industry. $J N C I$ 1969;43:249-52.

5 Sorahan T, Parkes HG, Veys CA, Waterhouse JAH. Cancer oे mortality in the British rubber industry: 1946-80. Br J Ind Med 6 1986;43:363-73.

6 Schifflers E, Jamart J, Renard V. Tobacco and occupation as risk factors in bladder cancer: a case-control study in southern $\mathrm{O}$ Belgium. Int J Cancer 1987;39:287-92.

7 Rinsky RA, Smith AB, Hornung R, et al. Benzene and leukemia. An epidemiologic risk assessment. $N$ Engl $J$ Med $C$ 1987;316:1044-50.

8 Central Institute of Statistics (ISTAT). Annuario statistico $\mathbb{D}$ Italiano. Rome: ISTAT, 1951-86 (various issues).

9 Decarli A, La Vecchia C. Cancer mortality in Italy, 1955-78. (La mortalità per tumori in Italia.) Tumori 1984;70, suppl:579-742.

10 Breslow NE, Day NE. Statistical methods in cancer research. Vol $\overrightarrow{0}$ 11. The design and analysis of cohort studies. Lyon: International $\infty$ Agency for Research on Cancer, 1987. (IARC sci publ No 82

11 Baker RJ, Nelder JA. The GLIM system: release 3. Oxfor Numerical Algorithms Group, 1978.

12 Cislaghi C, Decarli A, La Vecchia C, Laverda N, Mezzanotte G, Smans M. Dati, indicatori e mappe di mortalità tumorale Italia $\bar{O}$ 1975-77. (Data, statistics and maps on cancer mortality.) Bologna: Pitagora Editrice, 1986.

13 Matanoski GM, Elliott EA. Bladder cancer epidemiology. Epidemiol Rev 1981;3:203-29.

14 Decarli A, Peto J, Piolatto G, La Vecchia C. Bladder cancer mortality of workers exposed to aromatic amines: analysis of models of carcinogenesis. Br J Cancer 1985;51:707-12.

15 International Agency for Research on Cancer. Monographs on the evaluation of the carcinogenic risk of chemicals to humans. Suppl 7. Overall evaluations of carcinogenicity: an updating of IARC monographs vols 1 to 42. Lyon: IARC, 1988.

16 Foá V, Maroni M, Colombi A. Tossicologia e rischi per la salute nell'industria della gomma. Milan: Regione Lombardia, 1981.

17 La Vecchia C, Decarli A. Trends in cancer mortality in Italy, 19551978. Tumori 1985;71:201-18.

18 Peto J, Seidman H, Selikoff IJ. Mesothelioma mortality in asbestos workers: implications for models of carcinogenesis and risk assessment. Br J Cancer 1982;45:124-35.

19 Day NE, Brown CC. Multistage models and primary prevention of cancer. JNCI 1980;64:977-89.

20 Brown CC, Chu KC. A new method for the analysis of cohort $N$ studies: implications of the multistage theory of carcinogenesis applied to occupation arsenic exposure. Environ Health $\mathrm{O}$ Perspect 1983;50:293-308. 